\title{
Consumer impacts on dividends from solar water heating
}

Frances Hill \& Henrietta Lynch \& Geoff Levermore

F. Hil , G. Levermore: University of Manchester,Manchester, UK e-mail: Frances.hill@manchester.ac.uk

H. Lynch: Centre for Alternative Technology, Machynlleth, University of East London, London, UK

H. Lynch: University College London, London, UK

Keywords: solar thermal, auxiliary heating, consumer behaviour, legionella

\begin{abstract}
Common domestic solar water heating system usage patterns were investigated by a survey of 55 installations. These usage patterns were modelled by simulation based on the actual occupants' use of boiler or other auxiliary heating control strategies. These strategies were not optimal, as often assumed. The effectiveness of the technology was found to be highly sensitive to the time settings used for auxiliary water heating, and the $65 \%$ of solar householders using their boilers in the mornings were found to be forgoing $75 \%$ of their potential savings.
\end{abstract}

Additionally, 92\% of consumers were found to be small households, whose potential savings were only $23 \%$ of those of larger households, which use more hot water.

Overall the majority (at least 60\%) of the systems surveyed were found to be achieving no more than $6 \%$ of their potential savings.

Incorporating consideration of Legionella issues, results indicate that if solar thermal technology is to deliver its potential to $\mathrm{CO}_{2}$ reduction targets:

- solar householders must avoid any use of their auxiliary water heating systems before the end of the main warmth of the day,

- grants for solar technology should be focused on households with higher hot water demands, and particularly on those that are dependent on electricity for water heating,

- $\quad$ health and safety requirements for hot water storage must be reviewed and, if possible, required temperatures should be set at a lower level, so that carbon savings from solar water heating may be optimized. 


\section{Introduction}

The UK Government's projected carbon reductions from domestic solar water heating (DSWH) are being severely eroded by a lack of understanding from solar householders of how to achieve the best savings from their installations. This is exacerbated by the near absence of installation on larger households (Hill, 2008), with their higher consumption of hot water. The carbon reductions currently available from this technology are also severely impacted by the energy requirements of pasteurization routines for Legionella inhibition (ibid).

DSWH is the most widely installed renewable energy technology to date, with 78,000 installations recorded to 2006 , compared to 1,300 photovoltaic installations, which are the next most common (DTI, 2006, p16). The UK Government suggested in 2008 that 1.3 million DSWH systems would be installed by 2020 (Renewables Advisory Board, 2008), contributing to the $15 \%$ of all energy that is targeted to come from renewables by 2020 and the target of a $60 \%$ reduction in carbon emissions over 1990 levels by 2050. It is essential then, that DSWH should perform as expected.

DSWH is frequently quoted as reducing a household's fuel (or electricity) consumption for water heating by more than $50 \%$. Previous studies have either focused on comparison of different solar water heating systems in the laboratory (Martin and Watson, 2001, 2002), with no consideration of user variables, and predominantly without any auxiliary heat supply, or have monitored systems in use, but neglected to collect data on usage profiles, and due to major variations in installation pattern, and of parameters monitored, found that "comparison of data was difficult" (Bates et al, 1999). A fuller study has therefore been undertaken (Hill, 2008), involving a survey of solar households, their hot water demands, and their boiler programming patterns, and computer modelling of typical combinations of these.

DSWH is seen in the UK to carry a risk of Legionnaires Disease if water temperatures are not routinely raised to $60^{\circ} \mathrm{C}$. Kemna et al (2007) question the validity of this, and Hill (2008) reports on the outcomes of modelling the energy implications of different pasteurization regimes.

\section{Domestic solar water heating systems}

A typical DSWH system involves water in a storage cylinder being heated either "directly" by slow circulation through a rooftop solar panel or, more commonly, "indirectly", by a heat exchange coil at the base of the cylinder carrying a heat transfer fluid that is circulated through the rooftop panel. In each case, it is usual in UK to have a coil from a gas or oil-fired boiler or an immersion heater to supplement the heat in the same cylinder, raising the temperature to that 
required by the household (or for pasteurization - see discussion below). The fitting of the more common, indirect, system includes the supply of a purposebuilt cylinder, with the coil for the solar circuit at the bottom, and the coil for the auxiliary heating circuit around half-way up. The space below this second coil is described as the "dedicated solar volume", being heated only by the solar coil.
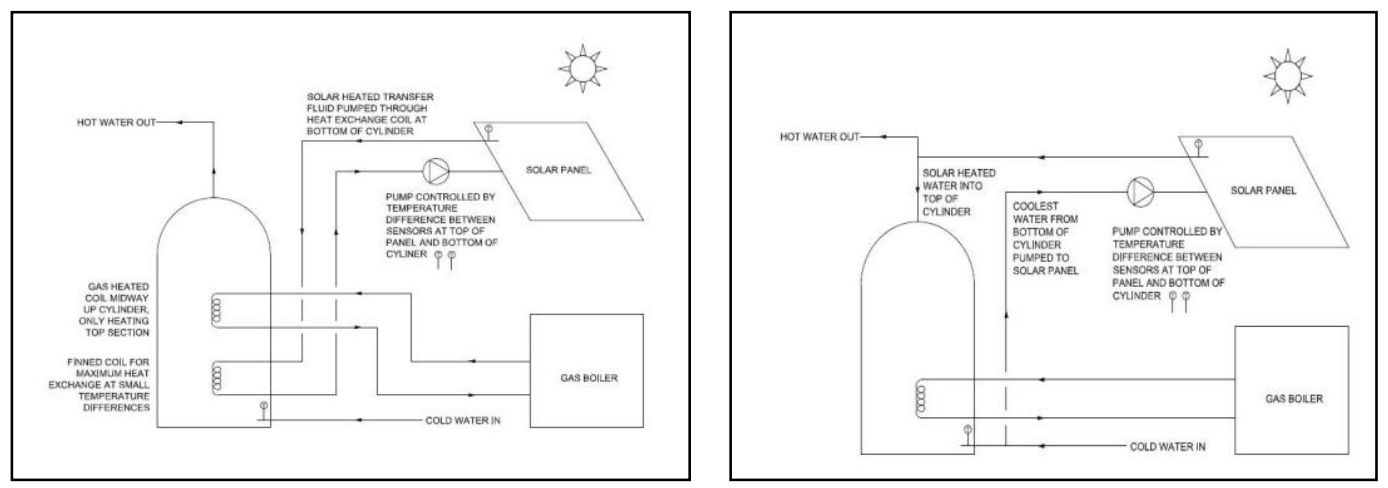

Figures $1 \mathrm{a}$ and $1 \mathrm{~b}$ showing the layout of active elements of indirect DSWH systems (1a), and direct DSWH systems (1b)

It is also possible to arrange a system with the tank above the collector, so that circulation occurs by gravity (and convection), but as this type of system is very seldom installed in UK, it is not considered here.

Two types of rooftop panel are used: flat plate, and evacuated tube. Both collector types use a heat absorbent black surface insulated from the surroundings, in close contact with a transfer fluid that is pumped through. In a flat plate collector, a heat transfer fluid is pumped through pipes in close contact with an extensive flat plate. An evacuated tube collector consists of a series of heat pipes, each in close contact with a heat absorbent fin, and encapsulated in an evacuated glass tube. The top end of each heat pipe connects in to a manifold through which the heat transfer fluid is pumped. Different manufacturers' panels of each sort vary in their precise configurations. The ranges of heat transfer efficiencies for the two collector types overlap, but most evacuated tube systems are found to be more efficient in UK conditions than systems with similar sizes of flat plate collectors.

The sizes of different elements of the system have an additional impact. The system will also incorporate an electronic pump controller that responds to temperatures at the outlet from the panel and at the bottom of the storage cylinder, pumping only when the temperature differential exceeds a set minimum. High levels of insulation on both pipework and cylinder are, of course, imperative for retention of heat, as in all stored hot water systems. 
Careful design of a system will take into account the household hot water demands, and then match panel and cylinder specifications to allow optimized potential, for minimized capital outlay. However, as seen below, this optimized potential will only be achieved if the auxiliary heating is also used in the best possible way, as the heat collection characteristics of all systems depend on the temperature of the water already in the cylinder.

\section{Usage patterns found by survey}

55 UK solar households were surveyed. An initial 15 households in the SK9 postcode area were identified by reconnaissance and word of mouth. A further 40 households across Britain responded to an appeal in the Quaker weekly publication "The Friend". Although the combined sample did not match the broader UK population, being composed largely of older and smaller households, it was seen to match closely the profile of households with solar installations found by a previous study (Sadler and Digby, 1995) both in terms of age and household size. It is therefore considered to reflect the profile of households nationally with $\mathrm{DSWH}$.

The scale and configurations of DSWH systems varied widely in many different respects, and it was recognized that a comparative analysis of system performance in terms of installation variables would require comprehensive energy use data, as well as hot water demand data. Historic energy use data (for periods from 1-20 years) was only made available by five of the households surveyed, and the timescale of the investigation did not allow for a sufficient period of further monitoring to pursue this route. Furthermore, the variation of usage patterns was striking, and was seen to merit investigative modeling.

Two elements of data from this survey were therefore combined in an exercise modeling the likely energy savings from installed DSWH systems:

The survey was used to establish the patterns in which householders used their hot water systems, and in particular, how they used their auxiliary water heating (boilers or immersion heaters) in tandem with their DSWH systems. The data is shown in Figures 2a and 2b.
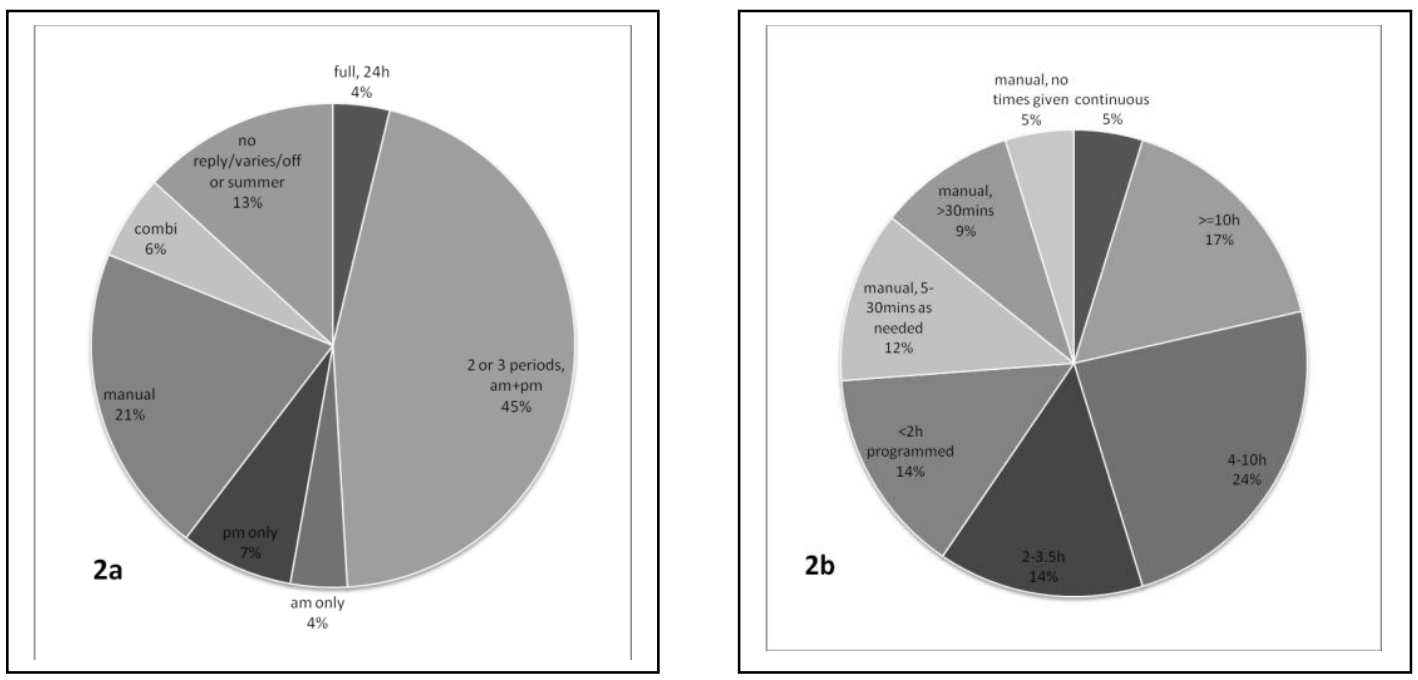
Figures $2 a, 2 b$ showing the times of day (2a) and lengths of time per day (2b) for which auxiliary water heating systems were used by households surveyed

Boiler use was found to range from continuous use down to "ten minutes when required". $65 \%$ of households in which the auxiliary heating supplied heat to water in the cylinder (as opposed to "combi" systems in which the water is heated in run-of-flow) were using their boilers to heat their water both morning and evening. From this, a series of patterns of boiler control were modelled.

The survey also provided data relating to the pattern of households that install and use solar water heating. It was found that $92 \%$ of solar households contained only one or two people, as shown in Figure 3. Only one household contained four people or more.

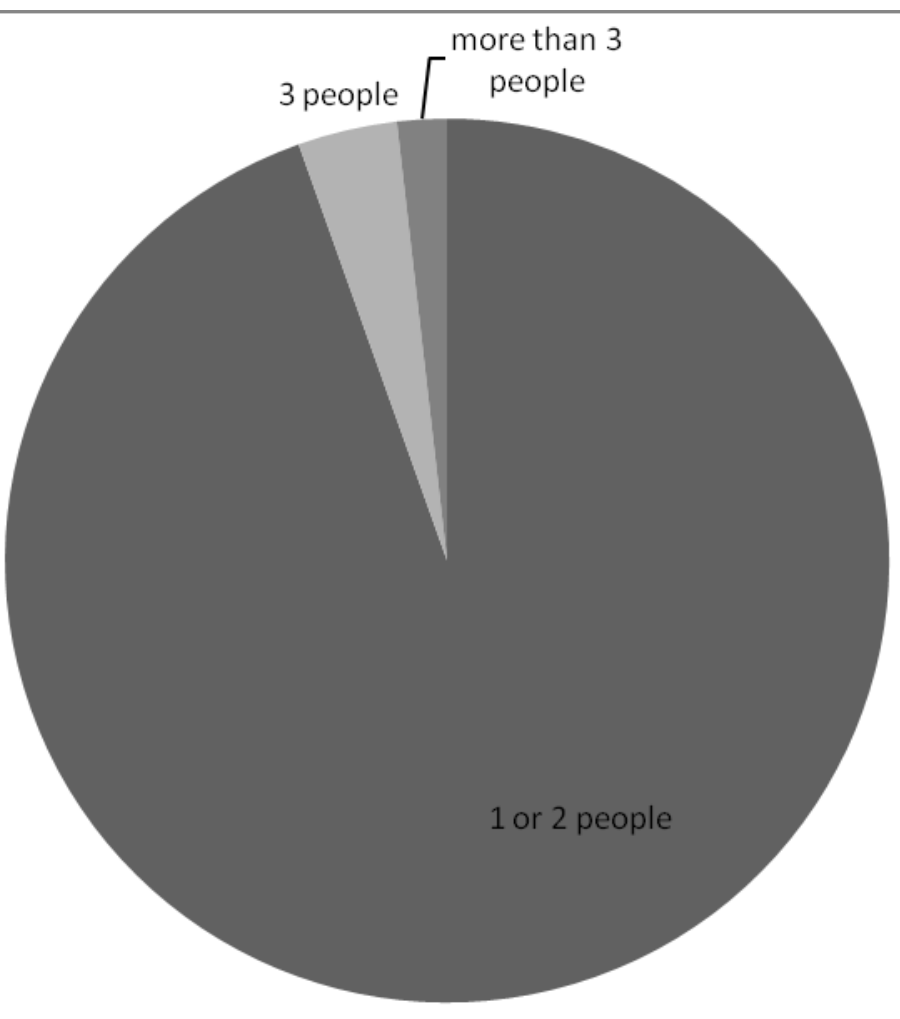

Figure 3: sizes of solar households

Reflecting this, two hot water usage patterns, based on 
i/ a two adult household taking two showers per day (50 litres at $45^{\circ} \mathrm{C}$ ), and

ii/ a larger household, with greater hot water needs, running two showers and one bath daily $\left(140\right.$ litres at $\left.45^{\circ} \mathrm{C}\right)$, were modeled. Both patterns included an allowance for other domestic purposes.

An indirect system was modeled, as this was the type used by $75 \%$ of the households surveyed, and a larger majority nationally. (This slight skew in the survey, not considered to be relevant to the investigation, was due to the fact that an installer of a direct system advertises regularly in the journal used to find solar households for the survey.) Typical sizes and values were used in modeling other elements of the DSWH systems (Hill, 2008). The systems were optimized according to the standard "rules of thumb" for cylinder and collector size, for both household sizes. Solar data for a typical year in Birmingham, England was used, as being similar in broad terms to that in much of UK.

\section{Potential savings determined by computer simulation}

TSol Pro, a solar thermal computer simulation package from Valentin Energie Software, which is sold as suitable for use by installers and suppliers, was used to establish the energy supplied by different elements of the hot water system when working on each combination of boiler control and hot water demand.

"Savings" were calculated as the proportion by which the fuel or electrical energy demand was lower than the amount of energy supplied as hot water. For this, all heat losses from pipes and storage counted as losses, reducing savings. This gave meaningful figures which, although low by comparison with those normally offered by the industry, compare more directly to the energy used by combi-boiler systems, which also avoid the losses associated with storage of hot water. 


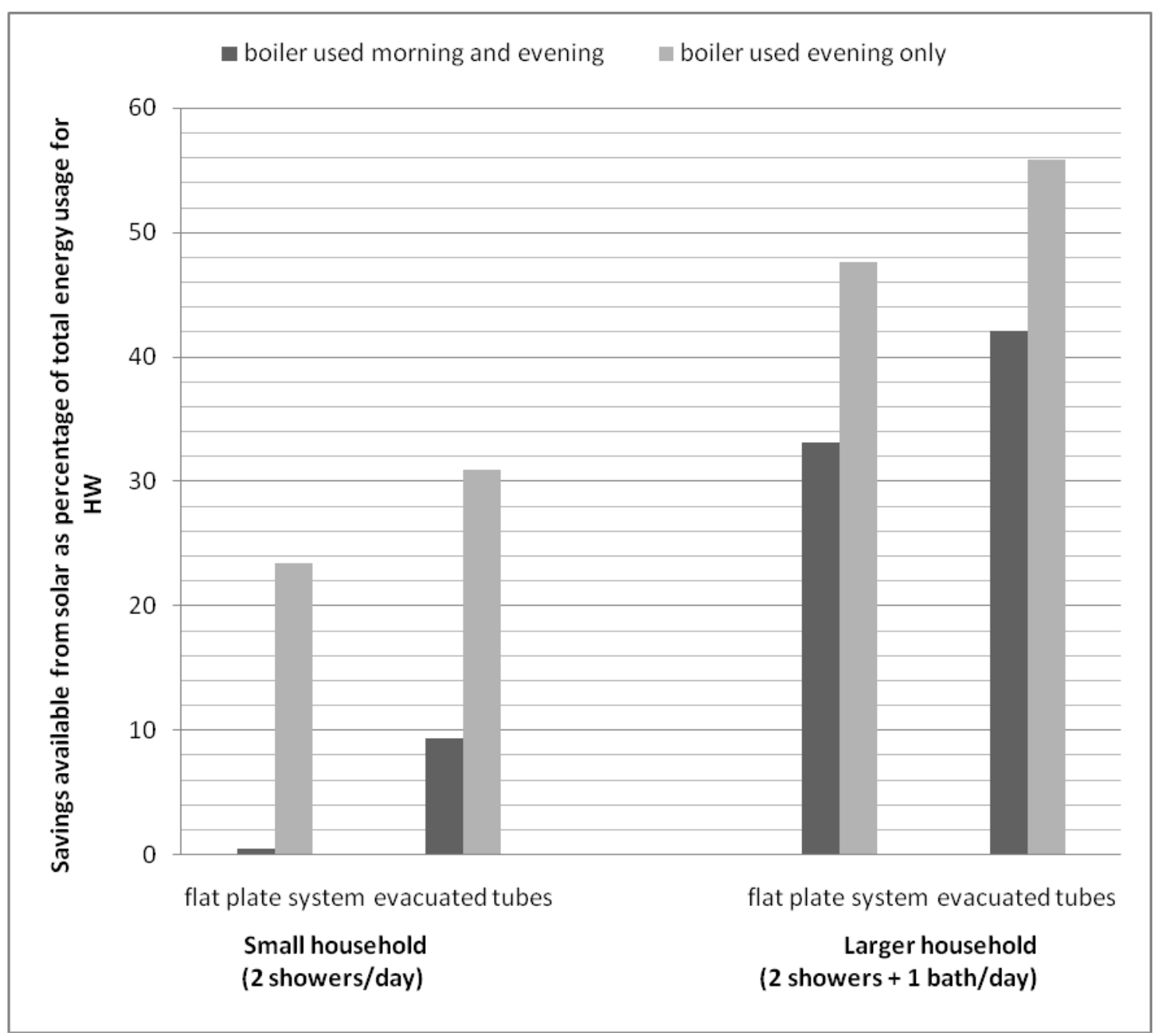

Figure 4: The percentage savings available for small and large households from use of the boiler for a single hour both morning and evening, and a single hour in the evening only. All systems supplied all hot water requirements.

It can be seen from Figure 4 that a solar installation saves a higher proportion of energy requirements for the larger family, with its higher hot water usage, than for the smaller household, and that the evacuated tube system gives better energy savings than the flat plate system. These results are, perhaps, both familiar and expected.

However, it can also be seen that the savings are increased very significantly by limiting the boiler use to evenings only. In this pattern, the boiler is used for an hour between 6 and $7 \mathrm{pm}$, after the main natural warmth of the day and before the first major demand for hot water. (The hot water can then be used any time after this, as it remains available, in the insulated cylinder). As hot water is subsequently drawn off from the top of the tank, it is replaced by cooler water, into the bottom. By leaving this unheated, the highest possible volume of water is cool at the start of the solar day, ready to be heated by the solar circuit. DSWH 
shows the highest efficiency in heating cooler water, its efficiency decreasing significantly as the water temperature rises.

\section{Most households don't know, and miss out on best savings}

Although it has been remarked that this pattern of boiler use "is just common sense", the survey showed that householders are not informed of this timing factor, and it is not the sort of common sense that many people know without being told it! Indeed, conversations with manufacturers' technical personnel suggest that they are not apparently aware of this factor (a technical representative of one installation company stated that "it doesn't matter what you do, solar will work for you anyway") and the installers they train are not therefore in a position to inform householders. As a result, a majority (65\%) of households surveyed were programming their boilers in a traditional pattern, boosting their water temperature both morning and evening, as seen in Figure $2 \mathrm{a}$, and missing out on significant savings.

A further factor that reinforces this pattern appears to be that most households' boilers are controlled by their pre-existing central heating timeswitch, which only allows choices of OFF, ON TWICE, ON ONCE, or ON (24 hours), with trigger points being the same for both central heating and hot water systems.

Clearly, householders must be informed of (and encouraged to use) patterns that will return the best savings, and solar installers must replace these timeswitches, as a matter of course, with more flexible programming controls.

\section{Household water usage impacts on absolute savings}

It has been seen in Figure 4 above, that a higher percentage saving is achieved by households with a higher usage of hot water. When the water usage is factored in, it can be seen, in Figure 5, that small households using less hot water save a disproportionately smaller amount of energy, typically less than a fifth of that saved by larger households that use more hot water.

Solar installations on small households are generally only a little smaller, and frequently very little less expensive, than those fitted on larger households, so that the payback period, in terms of either cash or carbon (embedded energy) is very much longer. 


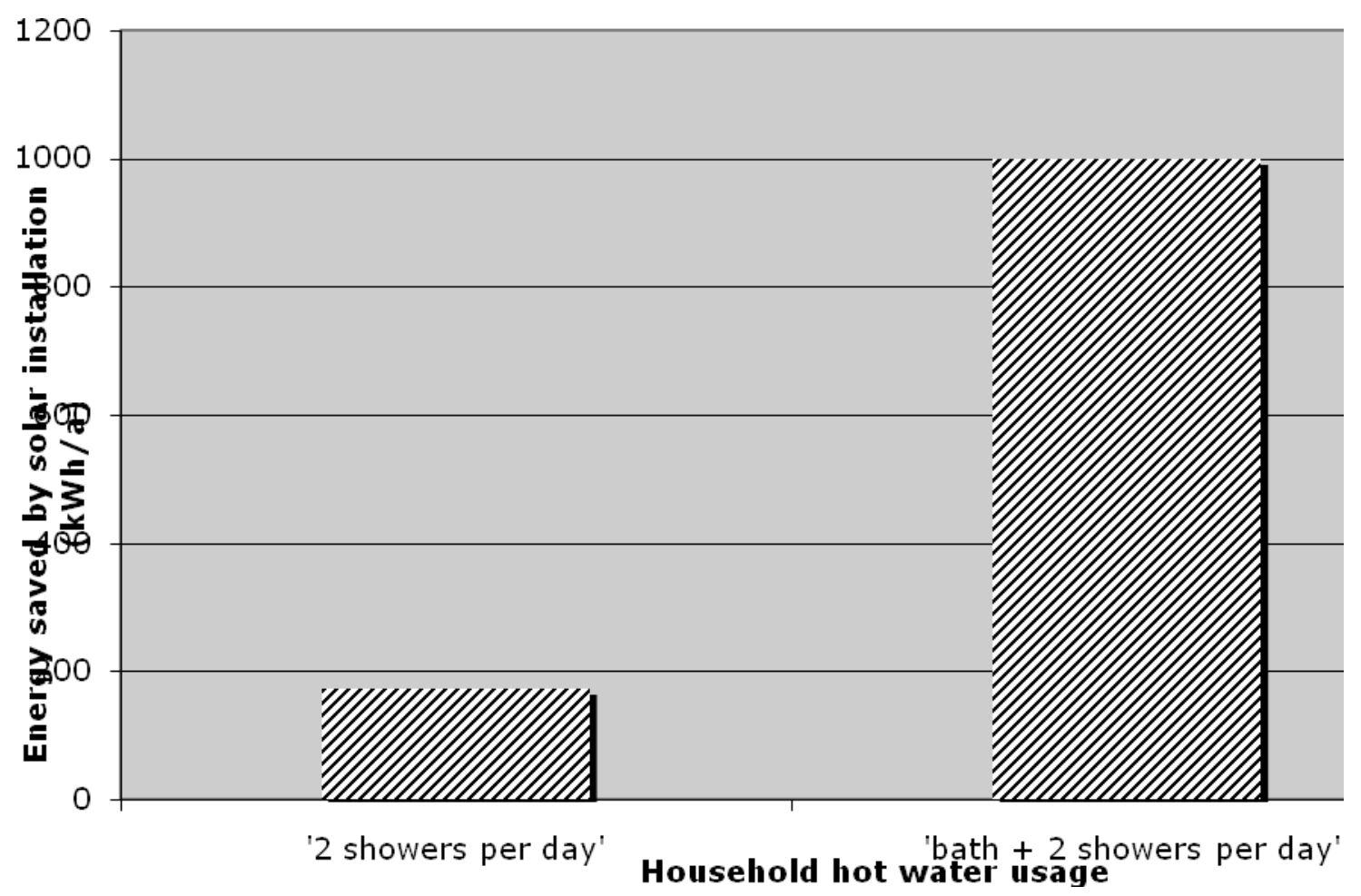

Figure 5: Comparison of energy saved by larger and smaller solar households (boiler operated in evenings only) (figures for a flat plate system, but similar comparison for an evacuated tube system)

The 2008 survey showed that the vast majority of solar households contained only one or two people, as shown in Figure 3. It appears that it is almost entirely retired individuals and couples who are investing savings or a lump sum in solar. Indeed, the only larger family among the sample had moved into a house that already had the solar system installed.

It can be seen that the combination of these factors is leading to domestic solar water heating technology severely underperforming its potential. It is clear that a means must be found to encourage or enable larger households, or those with higher hot water usage, to install solar, over and above incentives given to smaller users.

\section{Appropriate control of Legionnella}

The UK Health and Safety Commission (UKHSC) currently requires hot water to be kept at $60^{\circ} \mathrm{C}$ for an hour before use in order to pasteurize the water, killing legionella bacteria. This is based on the capacity of legionella to thrive in water between $25^{\circ} \mathrm{C}$ and $45^{\circ} \mathrm{C}$, and the high fatality rate of those with Legionnaires Disease. This demands significant extra energy input from the boiler. It is, however, arguable that, since there have been no identified cases of 
Legionnaires Disease, anywhere in the world, linked to a solar water heating system, this may be an unnecessary requirement.

To determine the energy implications of this issue, this heating requirement was modeled by increasing the period of boiler use to three hours per evening, to firstly ensure reaching the required temperature, and then to maintain that for a full hour. It can be seen in Figure 6 that this reduces savings by around $25 \%$. If using gas, this equates to around $50 \mathrm{~kg} / \mathrm{a}$ increase in carbon emissions for the larger family.

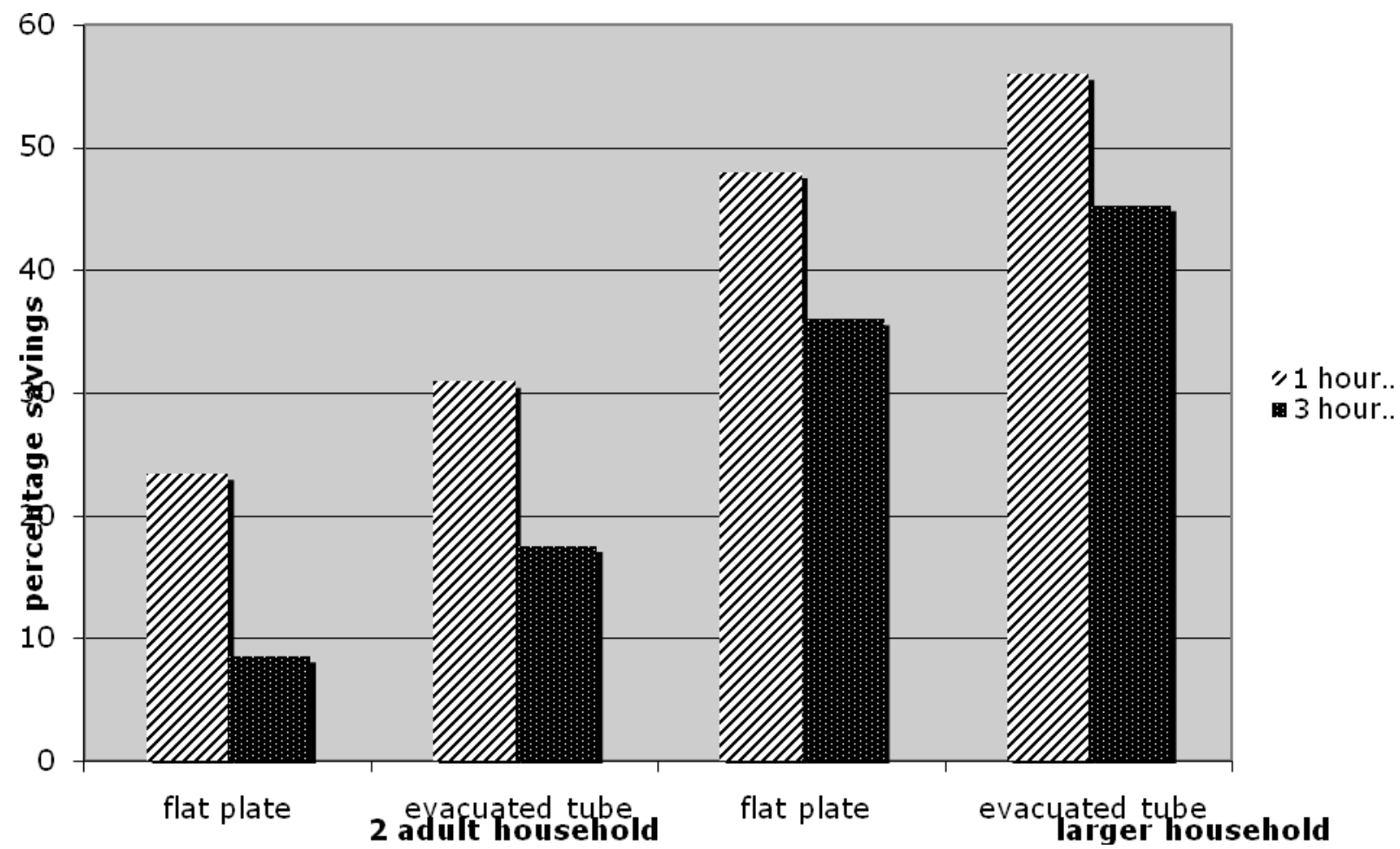

Figure 6: Impact on proportional savings of increasing boiler use to 3 hours to ensure pasteurization at $60^{\circ} \mathrm{C}$, compared with use of the boiler for a single hour

A research paper produced for the EU (Kemna et al, 2007) concludes that the requirement to hold water at $60^{\circ} \mathrm{C}$ for an hour is disproportionate, and "too blunt", especially for household DSWH systems. It suggests that since more than $90 \%$ of Legionella bacteria are killed within 2 hours at $50^{\circ} \mathrm{C}$, this is a more appropriate temperature on which to base a requirement. Indeed, US states restrict the upper temperature at which water may be stored to $49^{\circ} \mathrm{C}$ in order to prevent scalding, without any Legionella problems being seen (Hockey, 2002).

TSol does not enable access to the water temperature in the cylinder in the model, the available figures being, instead, the energy available to supply water at a set temperature. However, it is seen as likely that the earlier patterns modelled, of a single hour of boiler use, set to provide all the water required to 
the taps at $45^{\circ} \mathrm{C}$, would achieve this. Further modeling and practical experimentation could ascertain this.

\section{Solar saves more carbon when replacing oil or electric heating}

Figures 4, 5 and 6 above refer to the energy saved by the DSWH system. For most homes this energy comes in as gas, electricity or oil. The carbon savings from solar in replacing the use of electricity are significantly higher than when replacing gas or oil. Electricity production uses around 2.5 times more primary energy (most of which derives from coal, the highest $\mathrm{CO}_{2}$ emitting fossil fuel) to produce $1 \mathrm{kWh}$ than a gas fired boiler, and use of an immersion heater therefore causes the emission of more that 2.5 times more $\mathrm{CO}_{2}$ than heating it by gas. The carbon density of oil varies, but in general around $30 \%$ more $\mathrm{CO}_{2}$ is produced by burning oil to give $1 \mathrm{kWh}$ of heat than by burning gas (BRECSU, 2000).

\section{Combined impact of household size and boiler usage factors reduces} savings to $6 \%$ of potential; pasteurization reduces maximum savings by 25 $50 \%$

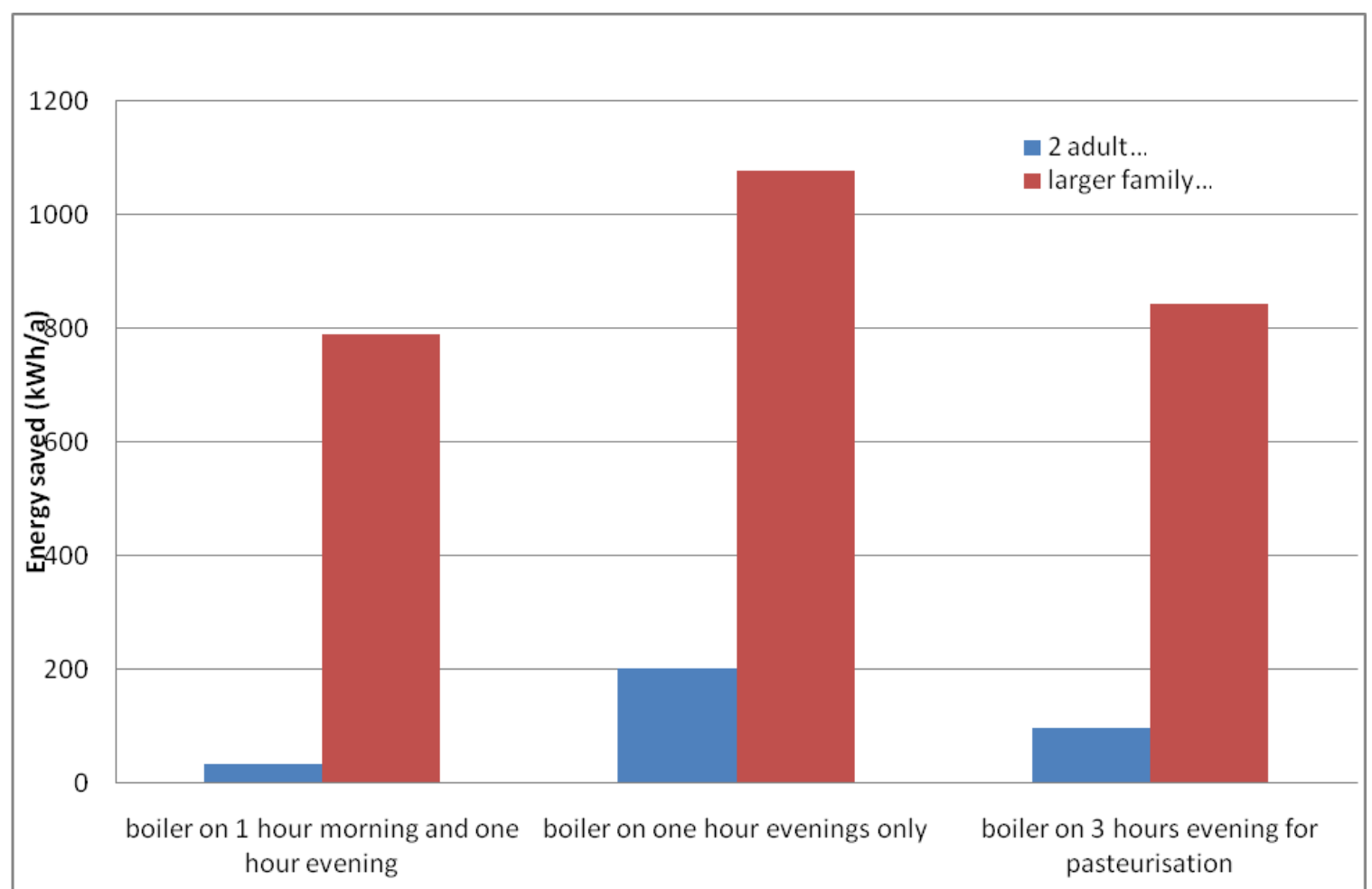

Figure 7 Comparison of energy savings from systems on smaller and larger households, with the boiler operated on three different regimes (all figures are averages of flat plate and evacuated tube calculations)

The combined impact of the above factors is to reduce the energy (and carbon) savings delivered by the majority of domestic solar water heating systems below the level that might be achieved by an optimally controlled installation on a larger 
household by at least a factor of 16 (a factor of 4 due to inappropriate timing of auxiliary heating, and a further factor of 4 due to household size) as shown in figure 7 . This means that they are delivering only $6 \%$ or less of their potential savings.

Figure 7 also shows the impact of the UKHSC pasteurization requirement on energy (and carbon) savings, by comparison with an auxiliary heating regime that delivers all required hot water.

\section{Conclusions}

In order for DSWH technology to fulfill its potential in delivering the carbon savings projected by the UK Government,

- Solar householders must be shown how to achieve the maximum savings from their systems, by timing all use of their auxiliary water heating system (boiler or immersion heater) to fall after the main natural warmth of the day, and before their first major demand for hot water, (the household is then free to choose whether to use the water in the evening or to leave it, staying hot, in the tank for the following morning)

- Incentivisation should initially be focused on larger households, with higher hot water demands,

- Priority should be given to households dependent on electricity for heating, and then to other areas without mains gas supplies,

- Further research is needed into safe regimes for solar water systems, so that water storage temperatures required by regulations can be set at the lowest appropriate level, to allow optimization of carbon savings from DSWH.

The UK Government's planned 1.3 million DSWH systems will then be able to contribute usefully to the carbon emissions reductions targets by 2020 .

\section{References}

Bates, J., Bertarelli, L., \& Schmidt, G., (1999), Active solar heating; system performance and data review, ETSU S/P3/00270/REP, Contractor: IT Power, DTI/ETSU, UK

BRECSU, (2000), Energy Use in offices: Energy consumption guide 19, Building Research Energy Conservation Support Unit, UK

DTI, (2006), Our energy challenge: microgeneration strategy: power from the people, Department for Trade and Industry, UK, www.dti.gov.uk/files/file27575.pdf

Hill, F., (2008), Consumer impacts on dividends from solar water heating, Unpublished MSc thesis, University of East London 
Hockey, R., (2002), Safe hot tap water and the risk of scalds and legionella infection, Injury Prevention, British Medical Journal 2002; 8;170

http://injuryprevention.bmi.com/cgi/content/full/8/2/170

Kemna, R., Van Elburg, M., Li, W., van Holsteijn, R., (2007), Preparatory studies on Eco-Design of water heaters, Van Holsteijn en Kemna BP, Delft, for European Commission

Martin, C., and Watson, M., (2001) Side by side testing of eight solar water heating systems, ETSU S/P3/00275/REP/2, DTI/Pub URN 01/1292, contractor: The Energy Monitoring Company, DTI/ETSU, UK

Martin, C., and Watson, M., (2002) Further testing of solar water heating systems, ETSU S/P3/00275/00/REP/3, DTI/Pub URN 02/1402, contractor: The Energy Monitoring Company, DTI/ETSU, UK

Renewable Advisory Board, (2008) 2020 vision - How the UK can meet its target of $15 \%$ renewable energy, Department for Business, Innovation and Skills, UK www.bis.gov.uk/files/file46652

Sadler, R., \& Digby, G., (1995), Survey of active solar heating systems in the United Kingdom, ETSU S/P3/00238/REP, DTI/ETSU, UK

TSol Pro, available from www.solardesign.co.uk 